\title{
Study of evaluation method for the overseas oil and gas investment based on risk compensation
}

\author{
Zu-Xin Li ${ }^{1,2}$ • Jian-Ye Liu ${ }^{1}$ Dong-Kun Luo ${ }^{1}$ Jian-Jun Wang ${ }^{2}$
}

Received: 14 November 2019 / Published online: 8 May 2020

(c) The Author(s) 2020

\begin{abstract}
The overseas oil and gas investment evaluation is one of the core tasks in overseas investment of oil and gas companies, among which risk evaluation and benefit evaluation are the most important. This paper sets forth transmission paths of risk factors to the investment benefit by identifying 14 overseas oil and gas investment risks in four categories. On the basis of the concept of risk compensation, different compensation mechanisms specific to each risk are designed. The risk and benefit are integrated objectively to develop a comprehensive evaluation model by correcting the recoverable reserve, adjusting benefit evaluation parameters such as investments on exploration and development, and compensating for the changes in risk factors with time through dynamic discount rate. Moreover, two cases studies, namely the evaluations of Project A in Sudan and comparison among Blocks A-G, are used to describe usage method and applicable scope of such evaluation model, respectively. According to the results, oil price is a key influencing factor for enterprise internal risk and industrial risk. Risk compensation reduces comprehensive benefit of overseas oil and gas investment and undermines the investment feasibility and priority of blocks. The research findings of this paper are free from the effects of some subject factors and avoid multi-objective decision making, and also avoid the undesired repeated calculation of risk factors.
\end{abstract}

Keywords Overseas oil and gas investment $\cdot$ Investment evaluation $\cdot$ Risk compensation $\cdot$ Dynamic discount rate $\cdot$ Comprehensive benefit

\section{Introduction}

Due to the growing oil demand, the crude oil dependency of China on imports has been ever increasing since the twentyfirst century. Major Chinese oil and gas companies develop their overseas development strategies for "Going Global" and carry out extensive overseas oil and gas investment campaigns. Therefore, investment evaluation of oil and gas reserves is of the extreme importance. In terms of the oil and gas investment evaluation, risk evaluation and benefit evaluation are the most essential parts.

Edited by Xiu-Qiu Peng

Dong-Kun Luo

ldkun@vip.sina.com

1 School of Business Administration, China University of Petroleum Beijing, Beijing 102249, China

2 Department of Overseas New Ventures Assessment, Research Institute of Petroleum Exploration and Development, Beijing 100083, China
However, on the one hand, with respect to risk evaluation of overseas oil and gas investment, risk levels of some factors may vary with time, e.g. political risks, oil price risks, etc. The timeframes, during which different risks occur, always differ. Obviously, exploration risks occur prior to sale risks. Therefore, it is difficult for a constant risk quantification value to capture such dynamic variation. On the other hand, in view of the benefit evaluation of oil and gas investment, the discounted cash flow method is often adopted to calculate the net present value of future cash flow, in which the discount rate (a key parameter) itself incorporates the economic connotation of risk compensation. Thus, extra risk evaluation may result in repeated calculation of some risks. Finally, overseas oil and gas investment decision making depends on the evaluation results in terms of both benefit and risk. When evaluation results are inconsistent, the selected decision criteria and approaches to translating into comprehensive evaluation indicators will also have an impact on the effectiveness of overseas oil and gas investment decision making. 
Therefore, with a view to addressing the above problems, it is necessary to identify static and dynamic risks in the oil and gas development process, and, respectively, design different risk quantification modes by analyzing the transmission paths of the impact of risk factors on investment benefits; incorporate compensation of static risks into various investment costs of oil and gas development, design dynamic discount rate to compensate for dynamic risks in the oil and gas production process, and integrate risks into the process of economic evaluation through compensation. This can not only rule out the possibility of recalculation of risks, but also effectively combine risk and benefit evaluation as a solution to the subjectivity of decision making under the dual objective criterion of benefit and risk.

\section{Literature review}

The purpose of the investment evaluation of overseas oil and gas assets is to support investment decision making. Accordingly, investment evaluation mainly consists of risk evaluation and benefit evaluations, with some references to evaluation results with respect to environmental protection, corporate strategies, etc.

As for the risk evaluation, most scholars (Ghandi and Lawell 2017; Xie et al. 2011; Yin 2011; Zhan et al. 2008) focus on risk factors in the field of exploration and exploitation, including the exploration risk, geological risk, reserve risk, technical risk, project risk and contract risk, etc. Some scholars (Wegener et al. 2016; Yang et al. 2014) take a more macro-perspective and focus on macro-environmental risks (including political and economic factors, sovereign credit risk and international oil price fluctuations). However, they fail to take into account and address the timedependent impacts of these risk factors. The above studies lack detailed identification, analysis and summarization of all risks of overseas oil and gas exploration and development investment. As quantification of risk factors as is concerned, many studies merely probe into the impact of a single risk factor on oil and gas development. Few studies (Dong et al. 2010; $\mathrm{Li}$ et al. 2017a conduct comprehensive analyses and adopt weighted risk factors to prioritize analyze oil and gas resource development, but they fail to analyze the inherent relationship between risk and benefit in detail.

As for the benefit evaluation, calculation of the net present value (NPV) by means of the discounted cash flow method is a practice accepted by most scholars and enterprises. On the basis of NPVs, a few scholars (Abadie and Chamorro 2017; Huang et al. 2018; Zhou and Yan 2013) introduce the real options method to calculate the value of the investment decision making right and calculate the optimal time of investment. Meanwhile, some other scholars (Gurgel et al. 2017; Liu and He 2008a, b; Zekri and Jerbi
2002) use NPVs to invert some economic limit parameters (such as the limit well density, well spacing, recovery rate and steam injection rate), which presents no breakthrough in a view of the discounted cash flow method. Discount rate is a core factor of discounted cash flow method. Many scholars have analyzed the risk discount rates of stocks and securities (Grandits and Thonhauser 2011; Lin and Yao 2012; Reinschmidt 2002; Rowse 2008), and sum up various asset pricing methods, such as APT Model, CAPM Model, and WACC. However, overseas oil and gas block investments see no the same developed trading market or frequent trading behavior as stocks or securities, and a small quantity of oil and gas resource trading cases are not enough to calculate the risk discount rate. Therefore, the fundamental Factor Accumulation Method is more applicable and practical. But the way to reasonably subdivide the accumulation factors and quantify all accumulation factors has become a new burning question.

As for the investment decision making under the dual objectives of risk evaluation and benefit evaluation, various scholars put forward different decision-making ideas. Mathematics and operations research professionals mainly prefer to carry out objective conversion or method improvement to resolve decision-making problems from a mathematical perspective: Decision-making objective conversion (Deng 2010; Zhu et al. 2013) is such a method that multiple decision-making objectives are converted into a single decision-making objective. For example, weighting is conducted for two objectives of risk and benefit according to a certain algorithm so that a comprehensive objective is calculated to make a decision. Decision-making method improvement (Fazlollahtabar and Saidi-Mehrabad 2015; Sorensen and Springael 2014; Wei 2012) takes advantage of a multi-objective algorithm for ranking. For example, the top $30 \%$ schemes, ranked by benefit, are selected at first. Among these schemes, the top $30 \%$ schemes, ranked by risk, are selected until the optimal scheme is finally selected. Oil and gas investment decision makers are more inclined to evaluate the process integration method. Guo et al. (2016) quantifies such factors as burial depth, resource quality and geographical location, and compensates for the risks into oil and gas reserves. Li et al. (2017b) clarifies risk level of resources according to the difficulty of exploitation and the quality of oil and gas, thereby alleviating the difficulty of decision making. Compared with mathematical methods, this type of method avoids the subjectivity of weight division or method design, which is more consistent with the actual situations of oil and gas development.

Such research idea largely prevails in this paper. Based on resource-related risk compensation method as described by Guo, this paper comprehensively gives consideration to the technical, economic and internal risks of overseas oil and gas investment; identify risk impact modes, compensate 
Table 1 Identification and classification of risk factors of overseas oil and gas investment

\begin{tabular}{|c|c|c|}
\hline Risk type & Risk factor & Brief description and remarks \\
\hline \multirow[t]{3}{*}{ Resource-related } & Resource quality & Crude oil quality, porosity, permeability, gas saturation, etc. \\
\hline & Resource characteristics & Depth, area, oil/gas content, reservoir layer pressure, etc. \\
\hline & Resource location & Climate type, geographic position, infrastructure, etc. \\
\hline \multirow[t]{6}{*}{ Technical } & Exploration technology & Seismic survey technologies, appraisal proficiency, etc. \\
\hline & Drilling and completion technology & Drilling design, equipment operation, drilling safety, etc. \\
\hline & Fracturing technology & Design and operation of fracturing, raw materials, equipment risk, etc. \\
\hline & Surface construction technology & Design alteration, material and structure risks, construction condition, etc. \\
\hline & Gathering and transportation technology & $\begin{array}{l}\text { Risks in pipeline network design, construction, corrosion, leakage and diffusion, } \\
\text { etc. }\end{array}$ \\
\hline & Production scheme & $\begin{array}{l}\text { Dewatering \& recovery technology, dewatering \& recovery system, alternative } \\
\text { plan, etc. }\end{array}$ \\
\hline \multirow[t]{3}{*}{ Economic } & Market environment & Market competition, demand, scale, price, etc. \\
\hline & Economic policy & Policies regarding taxes, subsidiaries, mining rights, environment protection, etc. \\
\hline & Financing environment & Interest rate, exchange rate, inflation, etc. \\
\hline \multirow[t]{2}{*}{ Internal } & Organizational capacity of enterprises & $\begin{array}{l}\text { Management system, decision-making mechanism, accident emergency mecha- } \\
\text { nism, etc. }\end{array}$ \\
\hline & Human resources management capacity & Personnel Redundancy/lack of labor force, etc. \\
\hline
\end{tabular}

for various static risks into various investment costs in the process of oil and gas exploration and development; design dynamic discount rate to present the changes in dynamic risks by subdividing the accumulation factors; and subsequently integrate various risks of oil and gas exploration and development process into the evaluation process of investment benefit through compensation. This can not only resolve the problem of dynamic changes in some risk factors, but also avoid the recalculation of risks in benefit evaluation and the subjectivity of decision making under dual objectives.

\section{Risk analysis of overseas oil and gas investment}

To effectively integrate risk evaluation and benefit evaluation and facilitate investment decision making, it is firstly needed to analyze risk factors of overseas oil and gas investment and their types, and then quantify their influence paths for development benefits, and incorporate them into the benefit evaluation process in the form of risk compensation.

\subsection{Identification and classification of risk factors for overseas oil and gas investment}

Extensive studies have been conducted on risk identification of overseas oil and gas investment. After generalization and summarization, the risk involved in overseas oil and gas investment fall into four types, namely internal risk of enterprises, macroeconomic and policy risks, resource risks of investment targets and possible post-investment technical risks. Types and descriptions of these risks are as shown in Table 1.

\subsection{Influence paths of risk factors to development benefits}

Risks factors have an impact on the future benefit of overseas oil and gas investment. Time and way these impacts occur are different for factors attributed to diverse risk types. Apparently, the oil price risk runs through the whole lifecycle of the investment and development, while exploration risk exists only at the exploration stage. The recovery cost depends on the depth of oil and gas resources, while resource quality is associated with sales price. In this regard, it is required to identify the influence path of each risk factor to development benefits, and design risk compensation mechanism in view of the transfer path of such influence.

Influence paths of risk factors to development benefits differ, which are realized by influencing the future cash inflow or outflow of overseas investment. The specific influence paths are as shown in Fig. 1.

It can be seen from Fig. 1 that there are different paths for risks of overseas oil and gas investment to influence future cash flow. Accordingly, risks occur in different time. Therefore, the above risks can further fall into the static and dynamic risks for the purpose of designing the risk compensation modes separately. Static risks are believed to only affect the cash flow of a certain item at a specific time point or within a short term, and in most cases present no change throughout the lifecycle (such as hydrocarbon 


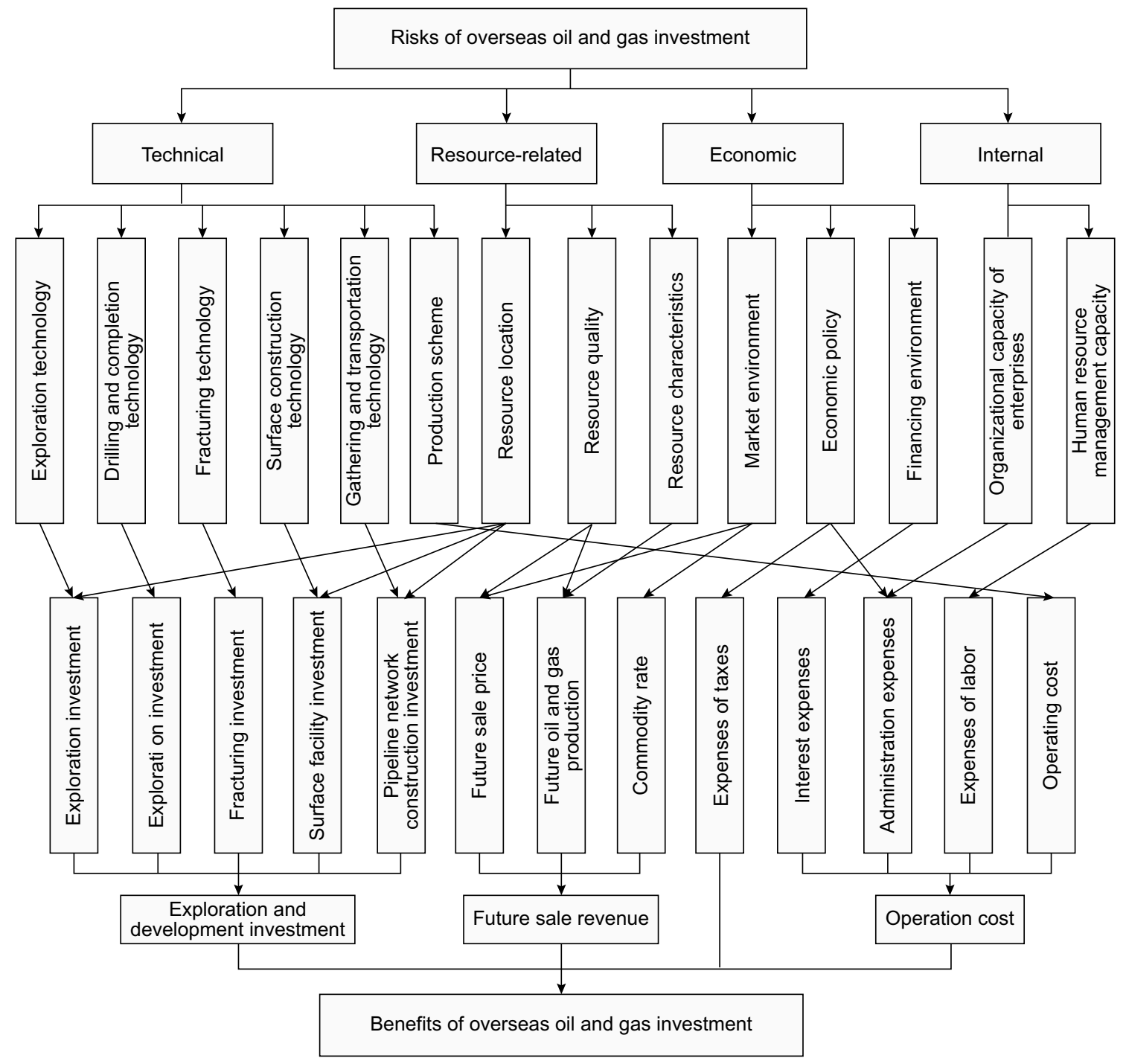

Fig. 1 Influence paths of risks in overseas oil and gas investment to investment benefits

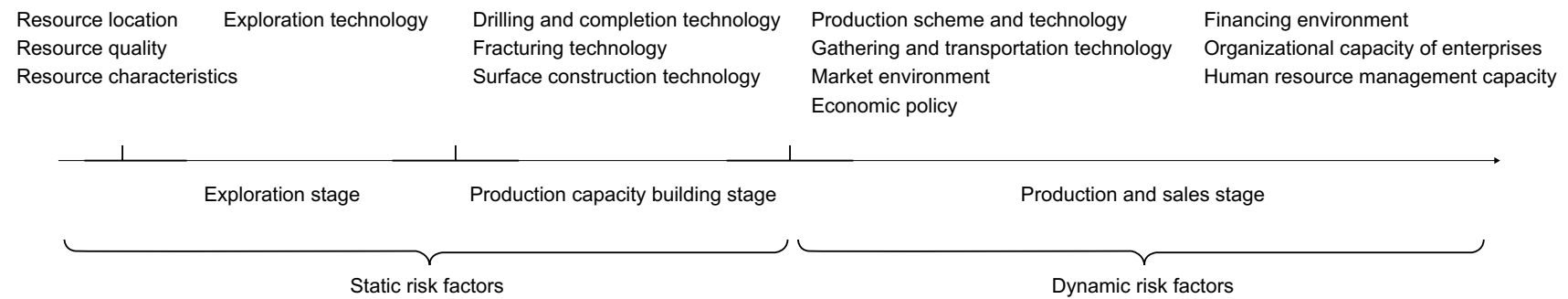

Fig. 2 Oil and gas development stages of investment risk factors

quality and resource characteristics). Dynamic risks are considered to prevail for a long time, impose a relatively long-term effect upon the cash flow of a certain item during the lifecycle, and constantly change throughout the duration (such as global oil price and interest rate of investment and financing). The analysis on the lifecycle of the risk factor is as shown in Fig. 2. 


\section{Design of compensation modes for risk factor}

The resource risk factors such as hydrocarbon quality, oil/gas bearing area and burial depth generally remain unchanged. The production capacity stage for oil and gas development lasts for 2-5 years, which is anticipated with no tremendous changes in development technologies. Nonetheless, the production and sale stage of oil and gas resource development can be up to 10-20 years, during which factors such as the global oil price, interest rate of investment and financing and production technologies are continuously evolving with time. Therefore, compensation modes of static and dynamic risk factors are required to be designed separately.

\subsection{Compensation design for static risk factors}

As for static risk factors, the benefit correction models related to a specific factor, proposed by many scholars, imply the concept of risk compensation for terrain variances (Zhu et al. 2016), contracts (Ghandi and Lawell 2017), resources (Guo et al. 2016), among others. However, all of these studies do not propose any complete design mode of risk compensation covering all risks in overseas oil and gas investment.

\subsubsection{Compensation design for resource-related risks}

In the compensation design of resource-related risks, Guo et al. (2016) quantify this type of risks in the recoverable reserve and argue that resource-related risks should be compensated by reserve correction, which is recognized and adopted in this paper. The reserve correction model is as shown in Eq. 1:

$N^{*}=N \cdot\left(1-S_{\mathrm{depth}}-S_{g}\right) \cdot S_{p} \cdot I O C \%$

where $N^{*}$ is the corrected reserve; $N$ is the original recoverable reserve; $I O C \%$ is shares held by the investor; $S_{\mathrm{depth}}$ is the correction factor for burial depth variances; $S_{g}$ is the correction factor under terrain variances; and $S_{p}$ is the adjustment factor for resource quality variances. For the details of correction factor calculation, please refer to the paper authored by Guo et al.

Herein follows a supplement for the model proposed by Guo et al. To begin with, although the effects of the resource quality are embodied ultimately by the sales price instead of the recoverable reserve, correction of reserves is essentially identical to adjustment of sales prices, which is not objectionable. Moreover, the technical advancement, technical risk and internal risks of enterprises are excluded in the model, which is obviously a defect. Moreover, as far as economic risk is concerned, the investment environment risk of each country is quantified and a risk coefficient is correspondingly developed to correct reserves, which is not recognized in this paper. The investment environment of each country evolves with time, which should neither be represented by a constant number nor be compensated with reserves. Instead, a dynamic compensation mode should be constructed, which will be introduced in the following section.

\subsubsection{Compensation design for technical risks}

In terms of technical risks, except the production technology, all the other technologies for exploration, drilling, fracturing and other aspects are deemed as static risks, since the duration of exploration and production capacity building is relatively short. Different investors may have varied technical capacities, and face up to different levels of risks. It is believed that technical risks would result in changes in investment. Accordingly, the correction based on technical risks is as shown as Eq. 2:

$I_{i}^{*}=I_{i} \cdot\left(1+S_{\mathrm{tec}-i}\right)$

where $I_{i}^{*}$ is the investment amount after the compensation for technical risk $i ; I_{i}$ is the theoretical investment amount when risk $I$ does not occur; $S_{\text {tec- } I}$ is the correction factor for technical risk $i$.

For risk correction factor, occurrence of risks has an impact on the actual investment amount, and the investment amount should gradually decrease due to the technical progress and learning effects. Therefore, Eq. 3 is used to quantify without thinking about technical progress and learning effects.

$S_{\text {tec- } i}=\frac{1}{n} \sum_{j=1}^{n}\left(I_{i j \text {-act }}-I_{i j \text {-exp }}\right) / I_{i j \text {-exp }}+S_{i \text {-study }}$

where provided that the constructor has accomplished $n$ similar projects, $I_{i j \text {-act }}$ is the actual investment amount of type $i$ investment for previous project $j$ under the effects of the risks; $I_{i j \text {-exp }}$ is the expected investment amount of type $i$ investment for previous project $j$; and $S_{i \text {-study }}$ is the correction coefficient for learning effects during the period of type $i$ investment.

It should be noted that due to the substantial existence of technical progress, the actual investment amount of a project may be lower than the expected investment amount, under which the calculated $S_{\text {tec- } i}$ may be negative. In fact, this correction does not only compensate for the technical risk, but also for technical progresses, which compensates for technical uncertainty in essence. 
Table 2 Annual average interest rates of the US 30-year mortgage loan, 1999-2019 (as of August 2019)

\begin{tabular}{|c|c|c|c|c|c|c|c|}
\hline Year & 1999 & 2000 & 2001 & 2002 & 2003 & 2004 & 2005 \\
\hline Annual average interest rate, $\%$ & 7.049 & 7.256 & 6.507 & 5.982 & 5.165 & 5.207 & 5.414 \\
\hline Year & 2006 & 2007 & 2008 & 2009 & 2010 & 2011 & 2012 \\
\hline Annual average interest rate, $\%$ & 6.067 & 6.022 & 5.265 & 4.577 & 4.102 & 3.693 & 2.935 \\
\hline Year & 2013 & 2014 & 2015 & 2016 & 2017 & 2018 & 2019 \\
\hline Annual average interest rate, $\%$ & 3.420 & 4.210 & 3.980 & 3.650 & 3.990 & 4.540 & 4.060 \\
\hline
\end{tabular}

\subsection{Compensation design for dynamic risk factors}

The static resource-related and technical risks are considered to maintain constant risk levels within a short term, for which risk compensation mode is designed according to the recoverable reserve and corresponding investment. Nevertheless, the production-technology, economic and internal risks are seen with long durations of effects, during which risk levels vary with time, and cannot be compensated via the reserve or a certain investment.

\subsubsection{Compensation design idea based on the dynamic discount rate}

Dynamic risks of overseas oil and gas investment mainly occur at production and sales stages. Only discount rate influences cash flow through these stages, which refers to the rate of return used to convert the future expected revenue within limited duration into the present value. Obviously, such factors as oil price, policy risk and investment and financing environment risks should be compensated with discount rate. In this paper, dynamic risk factors are compensated via the most direct Factor Summation Method, of which the model is given in Eq. 4:

$i^{*}=i_{0}+i_{\text {risk }}$

where $i^{*}$ is the discount rate of oil and gas investment; $i_{0}$ is the risk-free rate of return; and $i_{\text {risk }}$ is the risk compensation coefficient.

In accordance with risk identification as mentioned in Table 1, the discount rate under dynamic risk compensation can be calculated with Eq. 5:

$i_{t}^{*}=i_{0-t}+i_{\text {enterprise }-t}+i_{\text {industry }-t}+i_{\text {country }-t}+i_{\text {invest env }-t}$

where $i_{t}^{*}$ is the risk-compensation discount rate at year $t$ th of the oil and gas investment project; $i_{0-t}$ is the risk-free rate of return at year $t \mathrm{th} ; i_{\text {enterprise- } t}, i_{\text {industry- } t}, i_{\text {country- } t}$ and $i_{\text {invest env- } t}$ are the risk-compensation coefficients for the internal risk, industrial risk, risk and financing environment risk of host country of resources at year $t$. It should be noted that fluctuations of global oil price influence the whole industry. In this regard, the oil price risk should be incorporated into the industrial risk to avoid repetition.

In reference to the production technology risk, it should be included into operating expense like other technical factors, but should not be compensated with the discount rate, although it is a long-standing dynamic risk. The compensation mode for the production technology risk is as shown in Eq. 6:

$C_{\mathrm{opex}}^{*}=C_{\mathrm{opex}} \cdot\left(1+S_{\text {product tec }}\right)$

$S_{\text {product tec }}=\frac{1}{n} \sum_{j=1}^{n}\left(C_{\text {opex -jact }}-C_{\text {opex -jexp }}\right) / C_{\text {opex -j exp }}+S_{\text {product tec-study }}$

where $C_{\mathrm{opex}}^{*}$ is the operating expense after compensating the production technology risk; $C_{\text {opex }}$ is the theoretical operating expense free from the production technology risk; $S_{\text {product tec }}$ is the correction factor for the production technology; $C_{\text {opex- } j \text { act }}$ is the actual operating expense of the previous project $j ; C_{\text {opex- } j \exp }$ is the expected operating expense of the previous project $j$; and $S_{\text {product tec-study }}$ is the correction coefficient for the learning effects of the production technology.

\subsubsection{Risk-free rate of return}

Generally speaking, all actual interest rates are associated with risks at various levels, while risk-free rate of return is usually substituted by the financial interest rate with the least risk. Interest rate of the US 30 -year mortgage loan is herein adopted, ${ }^{1}$ and its data in the past 20 years are as listed in Table 2.

It can be seen from Table 2 that the US long-term loan interest rate stayed at a relatively high level from 1999 to 2008, and then fluctuated within the scope of 2.9-4.6 from 2012 to 2019 , and tends to periodicity. Thus, it is simply assumed that the future risk-free rate of return should be consistent to those over recent years. The future risk-free rate of return is as shown in Eq. 7:

$i_{0}(t+4)=i_{0}(t)$

\footnotetext{
${ }^{1}$ http://www.freddiemac.com/pmms/pmms30.html.
} 
Table 3 Average ROE of the oil and gas companies in fortune global 500 in 2018

\begin{tabular}{llll}
\hline Enterprise name & Profits, M\$ & Assets, M\$ & Total stockholder equity, M\$ \\
\hline Sinopec group & 5845.00 & $329,186.30$ & $105,181.50$ \\
Royal dutch shell & $23,352.00$ & $399,194.00$ & $198,646.00$ \\
China national petroleum & 2270.50 & $601,899.90$ & $291,198.60$ \\
BP & 9383.00 & $282,176.00$ & $99,444.00$ \\
Exxon mobil & $20,840.00$ & $346,196.00$ & $191,794.00$ \\
Total & $11,446.00$ & $256,762.00$ & $115,640.00$ \\
Chevron & $14,824.00$ & $253,863.00$ & $154,554.00$ \\
$\ldots$ & $\ldots$ & $\ldots$ & $\ldots$ \\
Total & $183,225.50$ & $4,381,228.30$ & Average \\
\hline
\end{tabular}

Table 4 Average ROE of the oil and gas production industry, 2013-2018

\begin{tabular}{|c|c|c|c|c|c|c|}
\hline Year & 2018 & 2017 & 2016 & 2015 & 2014 & 2013 \\
\hline Average ROE, \% & 10.66 & 7.62 & 5.98 & 6.95 & 13.04 & 15.67 \\
\hline $\begin{array}{l}\text { Industry risk compensation coef- } \\
\text { ficient, } \%\end{array}$ & 6.12 & 3.63 & 2.33 & 2.97 & 8.83 & 11.62 \\
\hline Average oil price ${ }^{\mathrm{a}}$ & 68.35 & 52.81 & 42.81 & 50.75 & 96.24 & 104.08 \\
\hline
\end{tabular}

${ }^{a}$ Annual average oil prices of Brent, Dubai and WTI crude oil: http://www.worldbank.org/en/research/commodity-markets

Equation 7 fails to accurately predict the annual future risk-free rates of return year by year, which is used to calculate the annual present values of the return from the future oil and gas investment, with cumulative errors subjected to accumulation and offset to some extent.

\subsection{Quantification of risk compensation coefficients for dynamic risks}

\subsubsection{Compensation coefficient for the industrial risk}

The average rate of return for an industry is the combination of the risk-free rate of return and the average risk premium in such industry, which can be calculated by means of CAPM Model or return on equity (ROE). Therefore, it is feasible to calculate compensation coefficient for the industrial risk using the industrial average return on assets, as shown in Eq. 8:

$i_{\text {industry }-t}=\mathrm{ROE}_{\text {average }-t}-i_{0-t}$

where $\mathrm{ROE}_{\text {average- } t}$ refers to the industrial average rate of return on equity at year $t$ th. ROE can be calculated according to the annual financial reports of companies. This paper focuses on 32 oil and gas production, refining and technical service companies among the Fortune Global $500^{2}$ in

\footnotetext{
2 https://fortune.com/global500/2019/search/?industry=Petro leum\%20Refining.
}

2019, and calculates their average ROE in 2018 (10.66\%), as shown in Table 3 .

The annual average ROEs of the oil and gas production companies among Fortune Global 500 are calculated, respectively, and the average ROEs of the industry over recent years are obtained. Oil price fluctuation presents the effects upon the average ROE of the industry, and the annual average oil prices and ROEs of the industry from 2013 to 2018 are as shown in Table 4.

Upon fitting, average ROE, industry risk compensation coefficient and average oil price of Oil and Gas Exploitation Industry show a high correlation. The fitting result is as shown in Eq. 9, where $P_{t}$ represents the annual average global oil price.

$$
\begin{aligned}
& \mathrm{ROE}_{\text {average }-t}=0.141 \% \cdot P_{t}+0.1287 \% \quad R^{2}=0.978 \\
& i_{\text {industry }-t}=0.143 \% \times P_{t}+3.9478 \% \quad R^{2}=0.975
\end{aligned}
$$

In terms of the future oil prices, no unified consensus has been reached among many scholars. Some scholars (Fonseca et al. 2017; Zhou and Yan 2013) hold the view that oil price fluctuation resembles the geometric Brownian motion, while others (Baumeister and Kilian 2015; Lee 2011; Xiaomei and Zhigang 2011; Zhang et al. 2012) forecast the oil price through support vector machine, Bayesian model, system simulation or combination method, which roll out different results. This paper holds such a view that oil price is characterized by mean-reversion with jumps (Zhou and Yan 2013). 
In other words, oil price is endowed with a mean-reversion nature, and the average oil price gradually rises with time under the premise of no unexpected outburst events. Fluctuations of future oil prices can be captured with Eq. 10:

$\mathrm{d} L n P_{t}=0.8\left(4-L n P_{t}\right) \mathrm{d} t+0.02 \mathrm{~d} z_{t}, \quad \mathrm{~d} z_{t} \sim(0, \mathrm{~d} t)$

where " 4 " is the logarithmic average of the oil price; " 0.8 " is the designed reversion rate; " 0.02 " is the designed logarithmic volatility of the oil price; and $\mathrm{d} z_{t}$ is the standard Brownian motion, i.e., $\mathrm{d} z_{t} \sim\left(0, \mathrm{~d}_{t}\right)$.

\subsubsection{Compensation coefficient for the internal risk of enterprises}

The internal risk of enterprises refers to potential loss caused by organizational capacity, human resource and management capacity, and different enterprises should adopt compensation coefficients for internal risk. The ROE of enterprises is regarded as the sum of the risk premiums of both enterprise and industry and the risk-free rate of return. Therefore, the compensation coefficient for internal risk of enterprises can be calculated with Eq. 11:

$i_{\text {enterprise }-t}=\mathrm{ROE}_{\text {enterprise }-t}-i_{\text {industry }-t}-i_{0-t}$

where $\mathrm{ROE}_{\text {enterprise- } t}$ is ROE of the investor enterprise at year th.

\subsubsection{Compensation coefficient for risks of host country of resources}

The risks of host country of resources include the risks associated with the sovereignty credit, policy, etc. Many investment intelligence organizations in the world make detailed scoring of investment risks for various countries. The operating risk ratings service, provided by the Economist Intelligence Unit (EIU), ${ }^{3}$ is mainly to evaluate operational and business risks of overseas investment. The evaluation includes ten factors and covers 180 countries, which is the most all-round for country risk and is applicable to calculation of the compensation coefficient of risks of host country of resources. In the rating system of the EIU, " 0 " represents the least risk, while " 100 " stands for the highest risk. Since the interest rate of the US long-term mortgage loan is chosen as the risk-free rate of return, investment risk of other countries should quantified, with the case of the US as the basis. The compensation coefficient for risks of host country of resources is developed, as shown in Eq. 12:

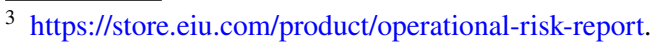

$i_{\text {country }-t}=\left(X_{\text {country }-t}-X_{\mathrm{USA}-t}\right) \% \cdot i_{0-t}$

where $X_{\text {country- } t}$ is the risk value of the selected host country of resources at year $t$ th; $X_{\mathrm{USA}-t}$ is the risk value of the US at year $t$ th.

\subsubsection{Compensation coefficient for investment and financing environment}

The investment and financing environment risk refers to such risks that investors assume for access to funds. Overseas oil and gas investment may not be completely made with investor's self-owned fund. Capital source is likely to include financing. The higher the investment and financing interest rate is, the higher the risk is posed for the investor, and so is the expected return on investment. Therefore, rate of interest in investment and financing should be taken into account when dynamic discount rate is made clear. It should be noted that the investment and financing environment to be evaluated is not the investment and financing environment of the host country of resources, but rather the country on which the investor is based. Taking CNPC (China National Petroleum Corporation) as an example, China's interest rate of investment and financing must be taken into account overseas oil and gas investment environment risk of CNPC, since CNPC has primary investment and financing channels in China. Moreover, for international investment and financing companies, the interest rate of investment and financing in multiple countries should be considered. The compensation coefficient for investment and financing environment can be expressed with Eq. 13:

$$
\begin{aligned}
i_{\text {invest env }-t}= & P_{\text {financing }} \cdot\left(R_{\text {financing }-t}-i_{0-t}\right) \\
& -P_{\text {Investment }} \cdot\left(R_{\text {Investment }-t}-i_{0-t}\right)
\end{aligned}
$$

where $P_{\text {finaning }}$ and $P_{\text {investment }}$ are, respectively, the proportions of external financing and external investment to the total investment; $R_{\text {finaning- } t}$ and $R_{\text {investment } t}$ are respectively the average financing interest rate and investment rate at the investment and financing environment where the investor is located, which are generally substituted by the local interest rate of long-term loan and interest rate of saving in such environment where the investor is located.

\section{Evaluation method based on dynamic risk compensation}

As mentioned above, identification and classification are made for risk factors, compensation modes are constructed for static and dynamic risk factors respectively, and the correction factors for static risk factors and compensation coefficients for dynamic risk factors are quantified. Evaluation 
model of overseas oil and gas investment can be developed through discounted cash flow method under risk compensation, thereby effectively integrating the risk evaluation and benefit evaluation.

\subsection{Brief introduction to discounted cash flow method}

Discounted cash flow (DCF) method, also called net present value (NPV) method, probes into the profitability of the project through the whole lifecycle. It can effectively mirror the development benefit of a project and highlight the characteristic of enterprises in pursuit of the maximum economic benefit, which is regarded as the most effective and feasible method for the oil and gas investment evaluation.
$C_{\text {opex }}$ is the operating expense; $C_{\mathrm{mng}}$ is the administration expense; $C_{\text {int }}$ is interest of financing; and $T_{\mathrm{x}}$ refers to taxes.

\subsection{Benefit evaluation model involved with risk compensation}

In the design of risk compensation, the resource-related risk factors should be compensated with recoverable reserve, the technical risk should be compensated with various investments, and the economic risks and internal risks of enterprises should be compensated with dynamic discount rate. In view of the time value of money, by substituting Eq. 15 into Eq. 16 with reference to Eqs. 1, 2, 3, 5 and 6, the benefit evaluation model of oil and gas investment under risk compensation is developed in Eq. 16:

$$
\begin{aligned}
\mathrm{NPV}^{*}= & -\sum_{t=1}^{N_{1}} I_{\text {exp }}^{*} \cdot\left(1+i_{t}^{*}\right)^{-t !}-\sum_{t=N_{1}}^{N_{1}+N_{2}}\left(I_{\mathrm{dri}}^{*}+I_{\text {fra }}^{*}+I_{\text {surf }}^{*}+I_{\text {net }}^{*}\right) \cdot\left(1+i_{t}^{*}\right)^{-t !} \\
& +\sum_{t=N_{1}+N_{2}}^{N_{1}+N_{2}+N_{3}}\left(N^{*} \cdot V_{t} \cdot P_{\text {market }} \cdot P_{t}-C_{\text {opex }-t}^{*}-C_{\text {mng }-t}-C_{\text {int }-t}-T_{x-t}\right) \cdot\left(1+i_{t}^{*}\right)^{-t !}
\end{aligned}
$$

NPV is the difference between the discounted cash inflow and outflow through the lifecycle of a project, which can be expressed with Eq. 14:

$\mathrm{NPV}=\sum_{t=1}^{n}\left(C_{\mathrm{I}}-C_{\mathrm{O}}\right)_{t}(1+i)^{-t}$

where NPV stands for the net present value of the project, with unit of USD 10,000; $C_{\mathrm{I}}$ is the cash inflow, with unit of USD 10,000; $C_{\mathrm{O}}$ is the cash outflow, with unit of USD 10,$000 ; i$ is the discount rate; $t$ is the sequence number of a year; and $n$ is the lifecycle of project, with unit of year.

For oil and gas development projects, the main cash inflow throughout the project lifecycle consists of the future sales revenue of oil and gas, while the major cash outflow comprises investments on exploration, drilling, fracturing treatments, surface facility construction and pipeline network construction, operating and administration expenses, wage of workers, interest and taxes. Therefore, the economic benefit through the full lifecycle of oil and gas development can be expressed with Eq. 15:

$$
\begin{aligned}
V= & R_{s} \cdot P_{\text {market }} \cdot P_{\text {oil }}-I_{\text {exp }}-I_{\text {dri }}-I_{\text {fra }} \\
& -I_{\text {surf }}-I_{\text {net }}-C_{\text {opex }}-C_{m n g}-C_{\text {int }}-T_{x}
\end{aligned}
$$

where $R_{\mathrm{s}}$ is the recoverable reserve; $P_{\text {market }}$ is the commodity rate; $P_{\text {oil }}$ is the sales price; $I_{\text {exp }}$ is the investment on exploration; $I_{\mathrm{dri}}$ is the investment on drilling; $I_{\text {fra }}$ is the investment on fracturing treatments; $I_{\text {surf }}$ is the investment on surface facility; $I_{\text {net }}$ is the investment on pipeline network construction;
Which is : $\quad\left(1+i_{t}^{*}\right)^{-t !}=\left(1+i_{1}^{*}\right) \cdot\left(1+i_{2}^{*}\right) \cdots \cdots\left(1+i_{t}^{*}\right)$

where $V_{t}$ is the oil/gas recovery rate, and other parameters are the same as those in Eqs. 1-6 and Eq. 15. The complete evaluation model for overseas oil and gas investment under whole lifecycle risk compensation can be obtained by substituting Eqs. 7-13 into Eq. 16. As the resultant equation is overwhelmingly complex, it is not presented herein.

\subsection{Examples of evaluation model}

The overseas oil and gas investment evaluation model based on risk compensation is primarily used to judge whether or not the oil and gas block is worthy of being invested, and also set investment priorities for multiple blocks. In this paper, seven blocks of CNPC in Africa and the Central Asia $(A-G)$ are selected for evaluation and comparison, among which Block A in Sudan is taken as an example to elaborately demonstrate the calculation method and workflow of the proposed model.

\subsubsection{The benefit evaluation process based on risk compensation of block $A$ in Sudan}

Block A, for which CNPC intends to invest, is located in Sudan, Africa. The recoverable reserve of this block totals 133.13 million bbl., with the resource burial depth of 2100 meters. It lies geographically in an onshore desert area. API gravity of crude oil is $21.6^{\circ}$, while sulfur content is $0.3 \%$. 
Table 5 ROEs of CNPC in 2013-2018

\begin{tabular}{|c|c|c|c|c|c|c|}
\hline Year & 2018 & 2017 & 2016 & 2015 & 2014 & 2013 \\
\hline Average ROE, \% & 4.37 & 1.91 & 0.66 & 3.02 & 9.02 & 11.44 \\
\hline $\begin{array}{l}\text { Internal risks compensation coefficient } \\
\text { of enterprises, } \%\end{array}$ & -6.29 & -5.71 & -5.32 & -3.93 & -4.02 & -3.60 \\
\hline Average oil price & 68.35 & 52.81 & 42.81 & 50.75 & 96.24 & 104.08 \\
\hline
\end{tabular}

Table 6 Interest rates of long-term loans over 5 years (23/12/2008-15/09/2019)

\begin{tabular}{llllllll}
\hline Time of change & $23 / 12 / 2008$ & $20 / 10 / 2010$ & $26 / 12 / 2010$ & $9 / 2 / 2011$ & $6 / 4 / 2011$ & $7 / 7 / 2011$ & $8 / 6 / 2012$ \\
\hline Interest rate, $\%$ & 5.94 & 6.14 & 6.4 & 6.6 & 6.8 & 7.05 \\
Time of change & $6 / 7 / 2012$ & $22 / 11 / 2014$ & $1 / 3 / 2015$ & $11 / 5 / 2015$ & $28 / 6 / 2015$ & $25 / 8 / 2015$ & $24 / 10 / 2015$ \\
Interest rate, $\%$ & 6.55 & 6.15 & 5.9 & 5.65 & 5.4 & 5.15 & 4.9 \\
\hline
\end{tabular}

Block $\mathrm{A}$ is subjected to production sharing contract, and investor intends to hold a $95 \%$ stake. The contract has a validity period of 25 years, including designed exploration stage of 2 years, production capacity building stage of 3 years, and the production and sales stage of 20 years. The expected exploration investment will amount to USD24.57 million; the drilling investment, USD30.8 million; the fracturing investment, USD26.82 million; the surface facility construction investment, USD60 million; the pipeline network construction investment, USD14.65 million. The oil recovery rate is expected to reach $2 \%$ (of the recoverable reserve per year), with decline rate of $20 \%$. The operating expense is USD $17.35 / \mathrm{bbl}$; the administration expense is USD $3.4 / \mathrm{bbl}$. Oil export yield tax rate is $11 \%$. Investor plans to raise $40 \%$ of the investment amount from the financing channel within China, which will be earmarked for early investment.

1. For resource-related risk factors: According to the correction factor calculation method proposed by Guo et al. (2016), ${ }^{4}$ IOC\% (the interests held by the investor) is $95 \%$ in Block A; the correction factor for resource burial depth $S_{\text {depth }}, 0.054$; the correction factor for geographical conditions $S_{g}, 0.063$; and the correction factor for resource quality $S_{p}, 0.7$. By substituting the aforementioned parameters into Eq. 1, the corrected reserve $N^{*}$ is calculated as 78.4745 million bbl.

2. For technical risk factors: On the basis of the previous oil and gas development experience of CNPC, the average deviations between the actual investments and the expected values in terms of exploration, drilling, frac-

\footnotetext{
4 http://apps.webofknowledge.com/full_record.do?produ $\mathrm{ct}=\mathrm{UA} \&$ search_mode $=$ GeneralSearch $\& \mathrm{qid}=1 \& \mathrm{SID}=8 \mathrm{Ejq} 2 \mathrm{ErIT} 8$ n66Y2VnyY\&page $=1 \&$ doc $=1$.
}

turing treatments, surface facility, operating expense and pipeline network construction are $40 \%,-4.55 \%$, $17.65 \%,-18.75 \%, 28.85 \%$ and $13.27 \%$, respectively. The correction coefficient for the learning effects is set as $2 \%$ (Yuan et al. 2015).

3. For internal and economic risk factors: According to relevant information of the securities issued by CNPC, ${ }^{5}$ the ROEs of CNPC in 2013-2018 are calculated, as shown in Table 5. It is believed that ROEs are also subjected to the global oil price. The result of fitting between the ROEs of CNPC and the average annual global oil prices is as shown in Eq. 17.

$$
\begin{aligned}
& \mathrm{ROE}_{\mathrm{CNPC}-t}=0.1646 \% \cdot P_{t}-6.315 \% \quad R^{2}=0.976 \\
& i_{\mathrm{CNPC}-t}=0.0335 \% \times P_{t}-7.3759 \% \quad R^{2}=0.836
\end{aligned}
$$

As $40 \%$ of the investment on Project A in Sudan is raised through financing from China, China's interest rate of loan should be considered. Changes in the interest rates of longterm loans ${ }^{6}$ in the past decade are as shown in Table 6.

Although China's interest rate of long-term loans presented the tendency of decline over the past decade, it has remained $4.9 \%$ since October 2015. Therefore, it is impossible to effectively predict the future changes in interest rates of loans. In the calculation, China's interest rates of loans are assumed to be a constant value of $4.9 \%$ in the long run. In addition, according to EIU, the risk score of the US is 20, which is 78 in Sudan. The dynamic discount

\footnotetext{
5 https://xueqiu.com/snowman/S/PTR/detail\#/ZYCWZB.

${ }^{6} \mathrm{https}: / /$ wenku.baidu.com/view/c704c8cdf424ccbff121dd36a32d73 75a417c6d9.html.
} 
Table 7 Calculation process and results of the future discount rate $i_{t}^{*}$, under risk compensation

\begin{tabular}{|c|c|c|c|c|c|c|c|c|}
\hline Year & 2019 & 2020 & 2021 & 2022 & 2023 & $\ldots$ & 2042 & 2043 \\
\hline$i_{0 t}$ & $4.06 \%$ & $3.65 \%$ & $3.99 \%$ & $4.54 \%$ & $4.06 \%$ & $\ldots$ & $4.54 \%$ & $4.06 \%$ \\
\hline$P_{t}(\$ / \mathrm{bbl})$ & 61.98 & 62.68399 & 63.85725 & 65.88171 & 64.587 & $\ldots$ & 78.52403 & 87.86544 \\
\hline $\mathrm{ROE}_{\text {average }-t}$ & $8.87 \%$ & $8.97 \%$ & $9.13 \%$ & $9.42 \%$ & $9.24 \%$ & $\ldots$ & $11.20 \%$ & $12.52 \%$ \\
\hline $\mathrm{ROE}_{\mathrm{CN} P C-t}$ & $3.89 \%$ & $4.00 \%$ & $4.20 \%$ & $4.53 \%$ & $4.32 \%$ & $\ldots$ & $6.61 \%$ & $8.15 \%$ \\
\hline$i_{\text {industry- } t}$ & $4.81 \%$ & $5.32 \%$ & $5.14 \%$ & $4.88 \%$ & $5.18 \%$ & $\ldots$ & $6.66 \%$ & $8.46 \%$ \\
\hline$i_{\text {enterprise- } t}$ & $-4.98 \%$ & $-4.96 \%$ & $-4.94 \%$ & $-4.89 \%$ & $-4.92 \%$ & $\ldots$ & $-4.59 \%$ & $-4.37 \%$ \\
\hline$i_{\text {country }-t}$ & $2.35 \%$ & $2.12 \%$ & $2.31 \%$ & $2.63 \%$ & $2.35 \%$ & $\ldots$ & $2.63 \%$ & $2.35 \%$ \\
\hline$i_{\text {invest env- } t}$ & $0.84 \%$ & $1.25 \%$ & $0.91 \%$ & $0.36 \%$ & $0.84 \%$ & $\ldots$ & $0.36 \%$ & $0.84 \%$ \\
\hline$i_{t}^{*}$ & $7.08 \%$ & $7.37 \%$ & $7.42 \%$ & $7.52 \%$ & $7.51 \%$ & $\ldots$ & $9.60 \%$ & $11.34 \%$ \\
\hline
\end{tabular}

Table 8 benefit evaluation process and results of block A in Sudan after risk compensation

\begin{tabular}{|c|c|c|c|c|c|c|c|c|}
\hline \multirow{2}{*}{$\begin{array}{l}\text { Stage } \\
\text { Year }\end{array}$} & \multicolumn{2}{|c|}{ Exploration } & \multicolumn{3}{|c|}{ Production capacity building } & \multicolumn{3}{|c|}{ Production and sales } \\
\hline & 2019 & 2020 & 2021 & 2022 & 2023 & 2024 & $\ldots$ & 2043 \\
\hline Oil price $\mathrm{P} t$ & 61.98 & 62.68 & 63.86 & 65.88 & 64.59 & 67.13 & & 87.87 \\
\hline Production volume/10,000 bbl & 0 & 0 & 52.31 & 104.63 & 156.94 & 125.55 & $\ldots$ & 1.81 \\
\hline$I_{\text {exp }}^{*}$ & 1744.47 & 1744.47 & 0 & 0 & 0 & 0 & 0 & 0 \\
\hline$I_{\mathrm{dri}}^{*}$ & 0 & 0 & 1000.49 & 1000.49 & 1000.49 & 0 & 0 & 0 \\
\hline$I_{\text {fra }}^{*}$ & 0 & 0 & 1069.67 & 1069.67 & 1069.67 & 0 & 0 & 0 \\
\hline$I_{\text {surf }}^{*}$ & 0 & 0 & 1665.00 & 1665.00 & 1665.00 & 0 & 0 & 0 \\
\hline$I_{\text {net }}^{*}$ & 0 & 0 & 562.90 & 562.90 & 562.90 & 0 & 0 & 0 \\
\hline$C_{\text {opex }-t}^{*}$ & 0 & 0 & 1187.64 & 2375.28 & 3562.93 & 2850.34 & $\ldots$ & 41.08 \\
\hline$C_{\text {mng- } t}^{*}$ & 0 & 0 & 177.87 & 355.73 & 533.60 & 426.88 & $\ldots$ & 6.15 \\
\hline$C_{\mathrm{int}-t}^{*}$ & 34.19 & 68.38 & 87.15 & 36.29 & 11.50 & 0 & $\ldots$ & 0 \\
\hline$T_{x-t}$ & 0 & 0 & 367.46 & 758.23 & 1114.99 & 927.17 & $\cdots$ & 17.49 \\
\hline Cash flow & -1778.66 & -1812.85 & -2777.60 & -930.60 & 615.20 & 4224.44 & $\ldots$ & 94.27 \\
\hline Discount rate & 0.0708 & 0.0737 & 0.0742 & 0.0752 & 0.0751 & 0.0810 & $\cdots$ & 0.113 \\
\hline Discounted cash flow & -1652.70 & -1560.33 & -2113.30 & -685.76 & 419.29 & 2645.89 & $\ldots$ & 8.86 \\
\hline \multicolumn{4}{|c|}{$\mathrm{NPV}^{*}$ (Net Present Value after Risk Compensation)/USD 10,000 } & 4849.78 & & & & \\
\hline
\end{tabular}

rate can be calculated with the parameters as mentioned above, as shown in Table 7.

The oil price $P_{t}$ in Table 7 is obtained via one simulation based on the mean-reversion with jumps mode. For the purpose of consistency, the subsequent evaluations of Blocks A-G all adopt this set of simulated oil prices. In actual practice, the average of results can be obtained through multiple simulations.

4. To sum up, according to Eq. 16, the benefit evaluation value, i.e., $\mathrm{NPV}^{*}$ of Block $\mathrm{A}$ in Sudan after risk compensation is USD50.4443 million. The calculation process is as shown in Table 8.

According to calculation results, NPV of Block A in Sudan reaches USD14546.24 million, with a fixed discount rate of $10 \%$ currently specified by CNPC and without consideration to risk compensation, which is far higher than NPV after risk compensation. This implies that the pure benefit evaluation overestimates the actual benefit of the future development without compensation for such risk factors as the resource quality, burial depth, various technologies, policies and contracts, which may result in errors of investment decision making.

\subsubsection{Evaluation results, comparison and ranking of blocks A-G}

The benefit evaluation model for oil and gas project investment based on risk compensation cannot only evaluate the feasibility of a single project, but also be applied for comparison and selection among multiple projects. Seven overseas 
Table 9 Basic parameters for seven overseas oil and gas projects (A-G) of CNPC

\begin{tabular}{|c|c|c|c|c|c|c|c|c|}
\hline Block & Unit & A & $\mathrm{B}$ & $\mathrm{C}$ & $\mathrm{D}$ & $\mathrm{E}$ & $\mathrm{F}$ & G \\
\hline Host Country of Resources & I & Sudan & The Niger & Chad & South Sudan & Sudan & Kazakhstan & Brazil \\
\hline Investor enterprise & / & CNPC & CNPC & CNPC & CNPC & CNPC & CNPC & CNPC \\
\hline Recoverable reserve & $10,000 \mathrm{bbl}$ & 13,313 & 4691 & 31,427 & 9926 & 12,360 & 1003 & 19,200 \\
\hline Burial depth & $\mathrm{m}$ & 2100 & 3750 & 2400 & 1556 & 1850 & 1150 & 2400 \\
\hline Geographic condition and terrain & / & Desert & Swamp & Desert & Tropical rain forest & Desert & Mountain land & Ocean \\
\hline API & l & 21.6 & 30 & 40 & 35 & 33.5 & 39 & 27 \\
\hline Sulfur contents & I & $0.30 \%$ & $0 \%$ & $0 \%$ & $0.10 \%$ & $0.10 \%$ & $0.30 \%$ & $0.1 \%$ \\
\hline IOC\% & l & $95 \%$ & $100 \%$ & $100 \%$ & $41 \%$ & $40 \%$ & $100 \%$ & $20 \%$ \\
\hline Exploration stage & Year & 2 & 3 & 2 & 5 & 5 & 1 & 7 \\
\hline Production capacity building stage & Year & 3 & 1 & 3 & 2 & 2 & 1 & 3 \\
\hline Production and sales stage & Year & 20 & 16 & 20 & 18 & 18 & 23 & 25 \\
\hline$I_{\exp }$ & USD10,000 & 2457 & 5249 & 14,209 & 5247 & 8094 & 738 & 15,860 \\
\hline$I_{\mathrm{dri}}$ & USD10,000 & 3080 & 6738 & 27,876 & 16,222 & 11,248 & 1429 & 28,740 \\
\hline$I_{\text {fra }}$ & USD10,000 & 2682 & 4283 & 17,719 & 10,311 & 7149 & 908 & 24,298 \\
\hline$I_{\text {surf }}$ & USD10,000 & 6000 & 6026 & 16,071 & 8041 & 3729 & 1202 & 46,052 \\
\hline$I_{\text {net }}$ & USD10,000 & 1465 & 513 & 3435 & 1085 & 1351 & 110 & 31,043 \\
\hline Recovery rate & l & $2 \%$ & $1.50 \%$ & $1.20 \%$ & $1.70 \%$ & $1 \%$ & $1.22 \%$ & $2.2 \%$ \\
\hline Decline rate & l & $20 \%$ & $15 \%$ & $15 \%$ & $15 \%$ & $20 \%$ & $12 \%$ & $15 \%$ \\
\hline$C_{\text {opex }-t}$ & USD/bbl & 17.35 & 13.68 & 5.66 & 11.98 & 19.98 & 6.91 & 8.07 \\
\hline Pipeline transportation expense & USD/bbl & 3.4 & 5.1 & 7.2 & 4.17 & 2.83 & 3.73 & 6 \\
\hline Tax rate & l & $11 \%$ & $17 \%$ & $20 \%$ & $8 \%$ & $11 \%$ & $11 \%$ & $15 \%$ \\
\hline Proportion of financing & / & $40 \%$ & $10 \%$ & $70 \%$ & $20 \%$ & $40 \%$ & $0 \%$ & $0 \%$ \\
\hline
\end{tabular}

Table 10 Benefit evaluation results of blocks A-G and the comparison

\begin{tabular}{|c|c|c|c|c|c|c|c|c|}
\hline Block & Unit & A & B & $\mathrm{C}$ & D & $\mathrm{E}$ & F & G \\
\hline npv* & USD 10,000 & 5044.43 & $-12,482.73$ & $19,368.17$ & $-11,365.28$ & -1015.93 & 123.56 & 3476.12 \\
\hline npv & USD 10,000 & $14,726.54$ & -3380.29 & $45,158.14$ & -4452.29 & 1312.78 & 551.06 & 4514.44 \\
\hline
\end{tabular}

projects $(\mathrm{A}-\mathrm{G})$ of CNPC are selected for evaluation, with the basic parameters as shown in Table 9.

The risk-free benefit NPV and benefit NPV ${ }^{*}$ after risk compensation are calculated for seven overseas oil and gas projects $(\mathrm{A}-\mathrm{G})$ of CNPC, respectively, and the results are as shown in Table 10.

From Table 10, it can be seen: (1) Benefit NPV*after risk compensation is always lower than the risk-free benefit NPV; (2) With consideration to risk compensation, the economic feasibility of oil and gas investment blocks may change (e.g., in Block E, NPV $>0$ changes to $\mathrm{NPV}^{*}<0$, which is economically unfeasible); (3) Priority of oil and gas investment projects may be altered after risk compensation. Under risk-free benefit NPV, investment priority is $\mathrm{C}>\mathrm{A}>\mathrm{G}>\mathrm{E}>\mathrm{F}>\mathrm{B}>\mathrm{D}$. Under benefit $\mathrm{NPV}^{*}$ after risk compensation, investment priority is $\mathrm{C}>\mathrm{A}>\mathrm{G}>\mathrm{F}>\mathrm{E}>\mathrm{D}>\mathrm{B}$.

\section{Conclusions}

This paper begins with identification and classification of risks in overseas oil and gas investment. On the basis of the concept of risk compensation, risk compensation modes for each identified risk have been constructed, in which the resource-related risk is compensated with recoverable reserve, the technical risk is compensated with exploration and development investments, and the internal risk of enterprises and economic risk are compensated with dynamic discount rate. Risk evaluation and benefit evaluation are effectively integrated, and the evaluation model based on risk compensation for overseas oil and gas investment is successfully developed. Examples are given to demonstrate the application method and applicable scope of the proposed model. The following conclusions have been drawn in this paper: 
1. The case study of Block A in Sudan demonstrates that overseas oil and gas investment evaluation should not only take into account development benefit, but also probe into risk factors in investment and development process so as to avoid overestimation of benefits and error of decision making. From the ranking of Blocks A-G, it can be seen that risk factors undermine comprehensive benefits and interfere with the investment feasibility and priorities of blocks.

2. In development course of model, it is found that the internal risk of enterprise and industrial average risk for oil and gas investment are highly connected with volatility of oil prices. In this regard, investors should pay high attention to the future oil price trends. The occurring time of different risk factors varies, and risk levels of factors may continuously change with time. A dynamic discount rate can sufficiently compensate the dynamic variation of risk factors.

3. The advantage of this method, as presented in this paper, lies in that risk factors are compensated separately in the benefit evaluation process. On the basis of transmission paths of risks factors, a comprehensive evaluation index is developed to objectively combine risks and benefits by using corrected evaluation parameters and dynamic discount rates. In this way, the effects of several subjective factors and the multi-objective decision-making problems are eliminated in the evaluation process. Moreover, the repeated calculation of the risk factors is avoided.

Open Access This article is licensed under a Creative Commons Attribution 4.0 International License, which permits use, sharing, adaptation, distribution and reproduction in any medium or format, as long as you give appropriate credit to the original author(s) and the source, provide a link to the Creative Commons licence, and indicate if changes were made. The images or other third party material in this article are included in the article's Creative Commons licence, unless indicated otherwise in a credit line to the material. If material is not included in the article's Creative Commons licence and your intended use is not permitted by statutory regulation or exceeds the permitted use, you will need to obtain permission directly from the copyright holder. To view a copy of this licence, visit http://creativecommons.org/licenses/by/4.0/.

\section{References}

Abadie LM, Chamorro JM. Valuation of real options in crude oil production. Energies. 2017. https://doi.org/10.3390/en10081218.

Baumeister C, Kilian L. Forecasting the real price of oil in a changing world: a forecast combination approach. J Bus Econ Stat. 2015;33(3):338-51. https://doi.org/10.1080/07350 015.2014.949342.

Deng YH. Multi-objective decision model of regional water resources' sustainable utilization. Commun Appl Math Comput. 2010;24(2):80-4 (in Chinese).
Dong Z, Wang Z, Zhao L, et al. Construction and application of risk rating and ranking model for international oil and gas exploration \& production projects. J China Univ Pet Ed Natl Sci. 2010;34(1):164-9 (in Chinese).

Fazlollahtabar H, Saidi-Mehrabad M. Optimizing multi-objective decision making having qualitative evaluation. J Ind Manag Optim. 2015;11(3):747-62. https://doi.org/10.3934/jimo.2015.11.747.

Fonseca MN, de Edson OP, de Victor EMV, et al. Oil price volatility: a real option valuation approach in an african oil field. J Pet Sci Eng. 2017;150:297-304. https://doi.org/10.1016/j.petrol.2016.12.024.

Ghandi A, Lawell C. On the rate of return and risk factors to international oil companies in Iran's buy-back service contracts. Energy Policy. 2017;103:16-29. https://doi.org/10.1016/j.enpol .2017.01.003.

Grandits P, Thonhauser S. Risk averse asymptotics in a BlackScholes market on a finite time horizon. Math Methods Oper Res. 2011;74(1):21-40. https://doi.org/10.1007/s0018 6-011-0347-4.

Guo R, Dongkun L, Xu Z, et al. Integrated evaluation method-based technical and economic factors for international oil exploration projects. Sustainability. 2016. https://doi.org/10.3390/su8020188.

Gurgel AR, Diniz AAR, Araujo EA, et al. Economical evaluation of heavy oil production from the Brazilian northeast. Energy Sour Part B. 2017;12(2):132-7. https://doi.org/10.1080/15567 249.2015.1079566.

Huang JY, Cao YF, Zhou HL, et al. Optimal investment timing and scale choice of overseas oil projects: a real option approach. Energies. 2018. https://doi.org/10.3390/en11112954.

Lee CY. Long-term crude oil price forecast using the bayesian model. POSRI Bus Econ Review. 2011;11(2):58-86 (in Korean).

Li H, Dong KY, Jiang HD, et al. Risk assessment of china's overseas oil refining investment using a fuzzy-grey comprehensive evaluation method. Sustainability. 2017a;9(5):18. https://doi.org/10.3390/ su9050696.

Li W, Dongkun L, Jiehui Y. A new approach for the comprehensive grading of petroleum reserves in China: two natural gas examples. Energy. 2017b;118:914-26. https://doi.org/10.1016/j.energ y.2016.10.125.

Lin HW, Yao JS. Pricing stocks by using fuzzy dividend discount models. Iran J Fuzzy Syst. 2012;9(3):61-78.

Liu HJ, He X. Evaluation method of well space density economic limit in oilfield. Toronto: Universe Academic Press Toronto; 2008a (in Chinese).

Liu JJ, He X. Economic evaluation on well space density in oilfield. Marrickville: Orient Acad Forum; 2008b (in Chinese).

Reinschmidt KF. Aggregate social discount rate derived from individual discount rates. Manage Sci. 2002;48(2):307-12. https:// doi.org/10.1287/mnsc.48.2.307.259.

Rowse J. On hyperbolic discounting in energy models: an application to natural gas allocation in Canada. Energy J. 2008. https://doi. org/10.5547/ISSN0195-6574-EJ-Vol29-NoSI-8.

Sorensen K, Springael J. Progressive multi-objective optimization. Int J Inf Technol Decis Mak. 2014;13(5):917-36. https://doi. org/10.1142/S0219622014500308.

Wegener C, Basse T, Kunze F, et al. Oil prices and sovereign credit risk of oil producing countries: an empirical investigation. Quant Finance. 2016;16(12):1961-8. https://doi.org/10.1080/14697 688.2016.1211801.

Wei XM. Ant-genetic algorithms based on multi-objective optimization. New York: IEEE. 2012. https://doi.org/10.1109/iccsn t.2011.6182321.

Xiaomei Z, Zhigang G. Simulation study on forecasting method of oil price forecasting. Comput Simul. 2011;28(6):361-4 (in Chinese).

Xie HB, Guo QL, Li F, et al. Prediction of petroleum exploration risk and subterranean spatial distribution of hydrocarbon 
accumulations. Pet Sci. 2011;8(1):17-23. https://doi.org/10.1007/ s12182-011-0110-8.

Yang YY, Li JP, Sun XL, et al. Measuring external oil supply risk: a modified diversification index with country risk and potential oil exports. Energy. 2014;68:930-8. https://doi.org/10.1016/j.energ y.2014.02.091.

Yin AZ. Study on economic evaluation index system of oil-gas exploration project. In: Advanced research on information science, automation and material system, Pts 1-6. Advanced materials research. Stafa-Zurich: Trans Tech Publications Ltd.; 2011. pp. 1693-1696. https://doi.org/10.4028/www.scientific.net/AMR.219-220.1693.

Yuan J, Dongkun L, Liangyu X, et al. Policy recommendations to promote shale gas development in China based on a technical and economic evaluation. Energy Policy. 2015;85:194-206. https:// doi.org/10.1016/j.enpol.2015.06.006.

Zekri AY, Jerbi KK. Economic evaluation of enhanced oil recovery. Oil Gas Sci Technol-Revue D IFP Energies Nouvelles. 2002;57(3):259-67. https://doi.org/10.2516/ogst:2002018.

Zhan LC, Yang M, Hu S. Risk Assessment and prevention in oil-gas exploration industry: the Tarim basin as the case. Toronto: Universe Academic Press Toronto; 2008. p. 257-62.
Zhang Y, Jia H, Tengfei Y. Research on petroleum price prediction based on SVM. Comput Simul. 2012;29(3):375 (in Chinese).

Zhou YQ, Yan L. Comparing two models for evaluating an oilfield development project: mean-reversion with jumps, geometric brownian motion. In: Sustainable development of natural resources, advanced materials research. Stafa-Zurich: Trans Tech Publications Ltd.; 2013, Pts 1-3. pp. 1568-1572. https:// doi.org/10.4028/www.scientific.net/AMR.616-618.1568.

Zhu L, Jiehui Y, Dongkun L. A new approach to estimating surface facility costs for shale gas development. J Natl Gas Sci Eng. 2016;36:202-12. https://doi.org/10.1016/j.jngse.2016.10.013.

Zhu M, Wu SD, Fu KC, et al. Research of multi-objective decision model based on SPA. In: Proceedings of 2013 2nd international conference on measurement, information and control. International conference on measurement information and control. New York: IEEE; 2013. pp. 847-850. https://doi.org/10.1109/ mic.2013.6758094. 